\title{
The roads less traveled
}

\section{Matthias Ruth}

\subsection{A call for exploration}

Environmental economics has, in principle, invaluable contributions to make to the health and wellbeing of people and the environment within which they live. It is a discipline concerned with the material and energy sources of our lifestyles, and the biophysical implications of our production and consumption choices. The conversion of materials and energy for the creation and delivery of desired goods and services contributes to and enhances livelihoods and standards of living, and also lies at the heart of all environmental problems. One could even argue that, because of the central role the transformation of environmental goods and services plays in fueling our economies and supporting our lifestyles, environmental economics does, and must, lie at the center of any endeavor to sustain the human enterprise; it cannot come as an afterthought, once other economic and policy issues are addressed.

Undoubtedly, though, insights from environmental economics rarely find themselves as preconditions under which other decisions are made. Analysis of and decision making on environmental issues are typically perceived as separable from other issues society needs to tackle. And such separation has not (yet) been perceived as a challenge to the longevity of the economic growth and development agenda that dominates economic policy. Rather, as environmental issues have been relegated to the sidelines of both the worlds of economics and of policy, unprecedented increases in wealth have been observed. Even in societies with much reduced access to that wealth and wealth generation potential, life expectancies, literacy rates and many other indicators of quality of life have, in aggregate, improved. So, why argue for a more central role of environmental economics in economics more generally and, more practically, in investment and policy making?

By most measures, many environmental conditions have worsened - ranging from fundamental disruptions of the global climate and their associated manifestations in the forms of increased frequency and severity of extreme weather conditions, fires, and rising sea levels, to severe reductions in the biodiversity that is so central to maintaining the fabric on which life on Earth, and thus also our food supplies, depends. Many more examples of such backlashes of environmental change on 
societies and economies could be listed here. The upshot is simple: Environmental degradation, sooner or later, comes back to affect us - be it in the form of direct impacts on our health or the indirect impacts we experience as ever more resources and energy need to be diverted to combat environmental insults, or because the loss of environmental quality deprives us of the joys and wonders that have previously come from living in a world of cleaner air and water for example, friendlier climate conditions, and habitats rich and diverse in the species they harbor.

While it has become clearer for decades that economic decisions must be judged against the backdrop of environmental performance, the implications of that observation for economic analysis and decision making have been less nuanced. For example, in the wake of two world wars, economic policy was largely oriented towards increasing economic output. New and more infrastructure enabled more rapid movement of people, raw materials, energy, water and other essentials for production. Expanded educational and health services improved the productivity of workers. A growing basket of affordable goods and services spread, in tangible ways, wealth into households, whetting their appetite for more.

Growing incomes and an expanding technological base provided households and firms with improved resources and abilities to prepare for, or respond to, undesirable conditions: people buying products that replaced previously available environmental goods and services, such as water filters to make up for a loss of clean water, or insurance against flooding in areas where previously ecosystems provided adequate flood control; or paying for advanced skills and education not just to better their position in an increasingly competitive work environment but to continue to expand their consumption, and thus improve their real or perceived standing in society; firms penetrating new markets locally or globally to diversify their resource base or expand into new areas in which to generate revenue streams; or public, private and non-profit entities providing services to combat droughts, wildfires, rising sea levels, invasive species and other ramifications of human-induced environmental changes. In short, economic growth has largely been perceived as a means to address a multitude of challenges, including the ones caused by economic growth. Such thinking can likely not be carried forward as critical thresholds in environmental performance are reached and surpassed.

The notion of environmental thresholds, and more generally the fact that many environmental systems must be maintained whole in some form, poses challenges for the kind of marginal analysis so common in economics: below a critical size or nutrient loading, a lake ceases to function as a lake; and beyond a level of fragmentation, a wetland stops providing its water purification and flood control functions. The analytical instruments that permeate the discipline do not readily lend themselves to the many real problems environmental economics must address.

In recent years, environmental economics, as an academic discipline, has become increasingly sophisticated in its treatment of environmental issues and the responses to them. One direction for improvement is associated with advanced mathematical 
prowess and expanded modeling capacities used to explore interactions between the economy and its biophysical environment. Research in this arena largely conforms to the standards and expectations of traditional economics, deploying and refining the tools of the trade that also proliferate other fields of the economics discipline. Computable general equilibrium modeling, behavioral economics, and game theory are just a few examples of such popular approaches. Compiling $A$ Research Agenda for Environmental Economics could easily draw on myriad authors engaged in these refinements and help point towards a future that is shaped by the incremental advances along existing trajectories. For this volume, I have chosen a more provocative approach, and instead turned to both experts within environmental economics and experts outside - researchers who are deeply knowledgeable of the challenges associated with conceptualizing, modeling and analyzing human-environment interactions and who understand the implications of such work for decision making at both micro and macro scales. The goal has been twofold - to question basic premises and point towards improvements, and to highlight through select examples the level of logic and analysis that must be brought to bear.

Of course, environmental economics is only one of the academic voices at the table of environmental analysis and decision making. If its point merely is to provide analyses - however sophisticated - within the echo chamber of its own peer group, then connecting with others may indeed be a distraction. In contrast, if there is at least some ambition to bring about solutions to the truly pressing and emerging environmental challenges that have begun to undermine economic prosperity, health and life itself, then an environmental economics that resonates with the theories and constructs of other disciplines may find itself as a valuable ally in problem solving. But, even without that ambition, those in the discipline who have begun to incorporate, for example, more physical or biological reality into their models have also differentiated their research from that of the masses, created a niche for themselves and often found it highly intellectually, if not professionally or socially, rewarding to embrace more of the complexities of human-environment interactions in their analyses than typically done.

\subsection{Where to go from here?}

One of the challenges for environmental economics stems from the fact that many of the environmental goods and services on which production and consumption depend do not have prices associated with them. Although that challenge has long been recognized - resulting in proposals, for example, to place levies on actions that result in undesirable outcomes or to provide subsidies that help avoid or negate them - the basic instrument set to overcome market failures has largely been market-focused. With markets in place, prices emerge that help reconcile competing interests and shepherd decisions towards Pareto-efficient outcomes. Among the many potential problems associated with this expansion of conventional economics thinking into the realm of environmental decision making, the following two may be worth highlighting. 
First, as the Austrian School of Economics repeatedly emphasized, "[b]uyers can see (some of) the prices at which some sellers are willing to sell, and sellers can see (some of) the prices at which buyers are willing to buy, but there is no information available to anyone about an equilibrium price" (Holcombe 2014, p. 12). The absence of global (conceptually, geographically and/or across time periods) equilibrium prices implies that local conditions dominate outcomes. Yet, actions that lead to local optima may not be consistent with actions to be taken when a larger set of buyer and seller interests are to be considered, when consequences are felt across geographies and over (long) periods of time. Yet, these are the very features that plague current environmental decision making.

A second and closely related problem stems from the fact that prices are not just the product of market interactions, but at a deeper level the result of historical and social conditions within which markets operate. Assuming well-functioning markets, rising prices would be associated with increases in the scarcity of a resource and stimulate a decline in demand and a search for alternatives. Where unintended consequences of production and consumption are encountered, externalities may be internalized to adjust prices and the signals they give to change behaviors and technologies. But what if the world is more complex than presumed here? What if prices are not only the product of rational economic decision making and instead reflect deep-seated social tensions and long-overlooked environmental constraints? For example, in societies in which women and children hold limited rights for selfexpression and self-determination, the wages paid to them for their labor will be depressed. In places where environmental standards are low, resource extraction and environmental pollution may cause harms that remain unaccounted for in economic decision making. The prices of goods and services in conditions of social and environmental exploitation are then not worth much with respect to their ability to guide economic decisions towards optimal outcomes (Røpke 1999; Ruth 2018). More likely, they will entrench unsustainable practices. Generally, prices may send flawed signals to decision makers, and as a consequence may be inadequate instruments to guide production and consumption choices towards desirable outcomes.

To more satisfactorily tackle, as an academic discipline and as a guide for real-world investment and policy making, the unique challenges that come from reconciling environmental change with economic change, environmental economics will need to simultaneously pursue two agendas. One of these concerns the true integration of insights from the physical and life sciences into models of production, consumption, environmental impact and feedback to the economy. The other must focus on the "human factors" - issues ranging from behaviors of individuals to institutional (including ethical and legal) considerations and the macro contexts from which they stem, such as the historical, cultural and social fabric within which people conceive of and address the challenges to which they must rise.

The first of these concerns, namely how to better integrate biophysical insights within environmental economics, is motivated by a range of observations. For example, if standard models of the conversion of materials and energy violate such 
fundamentals as the second law of thermodynamics, how can they be meaningful in guiding production or emission reduction decisions? If the conversion of materials and energy generates waste products with adverse impacts on human health and environmental quality, and those externalities manifest themselves over decades, can internalization be done in a timely enough fashion to be meaningful to those affected, not just as a conceptual but as a real solution to the problems at hand? Or shouldn't the models of environmental economics at the outset embed the biophysical information needed to anticipate harm? To pursue such a broader mandate for environmental economics requires much deeper collaboration with other disciplines to assure that the pathways by which economic decisions translate into impact are adequately captured, or that, at a minimum, the uncertainties surrounding such pathways are properly acknowledged.

Similarly, a macroeconomics that is built on the presumption that natural capital (soils, forests and oceans, for example) at best plays a marginal role in the generation of welfare woefully understates humanity's dependence on the environment to assimilate waste, and to provide the diversity and richness of species on which nutrient cycling, primary production and thus food supplies depend. It neglects the importance of stabilizing the climate within ranges to which social and economic processes have been calibrated for centuries. And none of these calls for fundamental reform of the discipline mentioned so far even cover non-utilitarian aspects of the environment, such as the contributions scenic beauty and tranquility may make to people's wellbeing, or the inspiration that may come from being in nature and which has found so many expressions in music and the visual arts, celebrated in concert halls, theaters and museums as cultural milestones of our societies.

\subsection{Appreciating the ethical, political and legal landscape}

In a diverse set of contributions - from women and men in both the northern and southern hemispheres, the worlds of academics and implementation, the field of economics and beyond - this volume focuses on what environmental economics has been, and must be, as humanity enters a new era of total dominance over all biogeochemical cycles, all species, and at every location on the globe. Mark Sagoff begins, in Chapter 2, by questioning the very tenets of conventional environmental economics: the notion that utility or benefit can be measured, compared between individuals and aggregated over society as a whole; and that the maximization of social welfare, perceived as the collective articulation of the benefits to individuals, is indeed an ethically desirable goal of society. The ability to measure benefit, in turn, is the basis on which to compare alternative actions, such as investment decisions or policy interventions to achieve more efficient outcomes. And the concept of social welfare allows for the identification of actions that would allow it to be optimized, given the very preferences on which welfare is defined. In short, the concepts of utility and benefit, and their measurement, provide the cornerstone for the use of economic analysis in decision making and for policy guidance. 
By focusing on markets, and the prices that are determined in them, as the mechanisms with which to promote optimality, environmental economics must treat a wide range of environmental goods and services - from soils and biodiversity to water purification, flood control and climate stability - much like ordinary commodities such as toothpaste, shoe laces, ballistic missiles and insurance schemes. Of course, no real markets exist formally for many of the environmental goods and services over which decisions must be made. However, in their absence, the existence and workings of markets may be inferred through a series of thought experiments in which people would be asked their willingness to pay for a good or service, or their willingness to accept that harm is done to the environment. Aside from the problems associated with the establishment of prices as neutral measures of value, or the fact that many environmental goods and services cannot be parsed into their constituent elements - no flood control of a wetland without adequate species diversity above and below ground, for example - or the presumption that individuals indeed are able to consistently judge the trade-offs they face, estimates of willingness-to-pay and willingness-to-accept have become mainstays in costbenefit analysis. They enable the discipline to draw from its tool chest the methods and models of market analysis. What it means to arrive in this way at an "optimal outcome", though, likely differs when beginning with a theory of the social good and analyses of what makes investment and policy decisions more effective rather than more efficient.

Beyond a fundamental rethinking of the theoretical foundations of environmental economics, Sagoff offers very practical guidance to those in the field. Understand and embrace the nuances that characterize, for example, the industries converting environmental goods and services, the technologies they use and the regulations that govern them - rather than begin with abstract mathematical constructs that are largely ignorant of those nuances! And attend to the social and technological trends that shape society, and thus the environment, such as the proliferation of artificial intelligence, increasing urbanization, demographic transition and aging, or rapid income redistribution within countries and across the globe, to name just a few. It is these practical, empirical issues that will help assure relevance of the discipline and those practicing it. The call for attention to many of these issues that shape human prosperity also reverberates throughout subsequent chapters of this volume.

Directly connecting with the observation that human-environment interactions manifest themselves in complex ways across time and geographies, and that conventional notions of optimality are flawed, Malte Faber and Marc Frick (Chapter 3) write of the importance of ignorance, responsibility and power of judgment as essential to the analysis of environmental problems. The conceptual and political foundation of environmental economics proposed by them is informed by the biophysical principles mentioned above - specifically the laws of thermodynamics that govern the conversion of materials and energy, and according to which any such conversion inevitably results in the joint production of (undesirable) waste materials and energy, whose recapture requires further resource expenditures. 
At a fundamental physical level, the laws of thermodynamics also place economic action along the continuum of time, given the irreversibility associated with the generation of waste from material and energy transformations. But there are other notions of time, such as those associated with evolutionary changes - that are themselves governed, of course, by physical laws - and which explicitly highlight the importance of novelty for any understanding of human-environment interactions, and the admission that surprises may challenge conventional wisdom.

Such a world, characterized by fundamental uncertainty and surprise, is very different from the world of conventional environmental economics where individuals, and the markets in which they act, behave in the fashion of Newtonian mechanics. Instead of maximizing an objective function (social welfare, for example), responsible action, informed by ethical reasoning, must guide the trade-off between desired outcomes on the one hand and, on the other, the many, often diffuse and little-understood, by-products that have impact on environment and society for a potentially long time to come.

Faber and Frick thus contrast the traditional homo oeconomicus, who is interested in the short term, with homo politicus, who is interested in justice, the common good and the long-term, sustainable state of natural living conditions. Heeding Sagoff's advice, they analyze the performance of the soda-chlorine industry over its roughly 300-year history, with an eye towards the roles individual inventors and institutions have played in not only creating new products and markets but also a host of environmental challenges that, themselves, had to be addressed with new technologies and regulations. All this, of course, has been characterized by considerable uncertainties and surprises along the way, which would have rendered any attempt at formal optimization irrelevant to the individual decisions that needed to be made at any given point in time or any given place. What it calls for, instead, is attention to the condition of the whole, the political community and the common good.

Returning to the recognition that the economy is a thermodynamically open subsystem of the larger ecosystems from which materials and energy are extracted and to which waste and heat are released, Deepak Malghan explores the relationship between the many competing needs of humans and how these may indeed be met (Chapter 4). He emphasizes that the choice between competing ends is inherently a moral exercise, not simply a process by which preferences are satisfied. In contrast, the traditional model of monetary exchanges, which dominates standard economics, emphasizes efficiency and optimality; it perceives social and political processes, as well as the physical environment, as separate and separable from the self-regulating processes of the market place. Malghan argues for a more prominent role of theories and methods from political economy in the treatment of human-environment interaction and the kind of new embedded ethics called for by Peter Brown and Geoffrey Garver (2009) that extends the focus on efficiency to include scale and justice as important determinants for long-term viable activities: the scale of the human enterprise relative to the environment's ability to provide 
goods and services; and attention to the distribution of the desired and undesired by-products across society.

Emphasizing the interplay of economic decisions, the workings of institutions and changes in the biophysical environment, Chapter 5, by Lee Breckenridge, explores the roles that environmental economics can have in evaluating institutional frameworks, and in particular the governance mechanisms that enable, limit and otherwise configure powers and responsibilities of owners, operators and regulatory authorities in organizing the ownership, management, exploitation and protection of the environment to serve societal goals. Understanding how property rights are formed, articulated and managed is central in this context. Although much of environmental economics presumes market-based exchanges to take place against the backdrop of given property rights, allowing for the appropriation and exchange of environmental goods and services, property rights are far from static and do change as economic growth and development, expectations and environmental change unfold. Property regimes are public goods that require collective action to define and operate, and evolve with their institutional underpinnings. The protocols that are established to monitor and enforce boundaries of property rights, track ownership over time and recognize and implement terms of contracts are key components of a market system, which in turn must evolve as protocols change.

The co-evolution of property rights and markets is essential to the calibration processes by which long-range repercussions in the coupled human-natural system must be addressed. In Breckenridge's words: "By looking closely at how human systems align and coordinate with the functioning of biophysical systems, economic research can illuminate, in effect, the design of institutions that represent successful examples of collective action to organize and control human behavior in interactive relationships with ecosystems." One goal of such alignment is the creation of resilient socio-economic systems, i.e. finding ways in which impacts of adverse environmental conditions and shocks on society can be minimized. Striving for resilience is a particular challenge in light of the considerable uncertainties and surprises that inevitably plague the coupled human-environment system as thresholds are approached and surpassed.

To what extent can markets promote resilience, with their anchor in defined property rights and the biases that come from adjusting to past and current signals on system behavior? To what extent does the pursuit of resilience promote sustainability, given that the material and energy needed to maintain infrastructures (hard and soft) may themselves contribute to the very environmental changes against which society intends to protect itself? How does one go about creating the kind of far-sighted institutions that reconcile historical experiences, and pressing and emerging social needs and interests, with long-term viable outcomes?

Clearly, economics in itself has been ill-suited to promote resilience and sustainability. What will be needed is an infusion of the moral and ethical imperatives of 
which Sagoff, Faber and Frick have written, and an interplay with the evolution of institutional and legal contexts within which markets must function. Experiences from the United States, for example, clearly illustrate the shortcomings of environmental policies that are, to a considerable extent, shaped by strong concepts of private property and persistent opposition to laws and regulations that challenge the interests of the establishment. As a consequence, the evolution of institutions to mitigate or prepare for environmental changes and shocks has been limited at best. Staggering evidence for deficiencies in policy-driven institutional responses to climate change, for example, can be found both on the mitigation and adaptation side of the problem - there are no federal policies that curb greenhouse gas emissions, and land use laws continue to impede the kind of land management practices needed for effective flood control. However, the United States, unfortunately, is not an outlier. Other countries, especially those with similarly close or closer alignment of economics with the political elites, exhibit similar challenges.

Where the very mechanisms by which markets signal the need for adjustments are in themselves constrained by undesirable social and environmental conditions, little may be expected of economics to help break out of the mold it created for itself. Conversely, where knowledge on how to change that mold can be infused in the models and analyses of environmental economists, the discipline should be able to meaningfully contribute to the solution of increasingly pressing and rapidly emerging social and environmental problems.

\subsection{Taking a macro view of economic activity in the environment}

Climate change as a fundamental threat to humanity is a recurring theme in this volume: in part because it is what will shape economic decision making for a long time to come; and in part because it poses challenges for the way environmental economics conceptualizes the feedback processes between society and the environment. It highlights some of the existing shortcomings in theory and practice, and it also offers valuable prompts for the discipline to incorporate insights from the biological and physical sciences, as well as ethics, policy and law as described above.

In an effort to describe the interdisciplinary lay of the land, as it were, within which economics must navigate, in Chapter 6 Martin Sers and Peter Victor sketch out how insights from biology and physics must shape development of environmental economics theory. For example, the marginal analysis of conventional integrated assessment models, many of which only capture unidirectional coupling between socio-economic and environmental changes (Motesharrei et al. 2016), is not particularly amenable to the non-linearities, bifurcations and surprises inherent in the real, bidirectionally coupled system. Using a simple arithmetic argument, they state that in macroeconomic models neither growth nor the factors that drive it should be assumed at the outset. Consistent with the arguments presented above, this holds especially in environmental macroeconomics where the physical dimensions of economic growth are of paramount importance. 
How then does one go about measuring macroeconomic performance in ways that establish, conceptually and empirically, consistent connections between some forms of environmental changes and changes in the economy? One such measure is the energy return on the energy that the economy uses to explore, extract, process, ship and otherwise make available to producers and consumers in the economy. Declining energy returns suggest that it gets tougher to provide energy, perhaps because technologies have approached performance limits that prevent them from compensating for a more diffuse resource base, or because environmental regulation stipulates the use of technological interventions that themselves require energy, and thus reduce the overall efficiency of the delivery system. Examples of the deployment of such technologies are the scrubbers used to combat sulfur emissions from power generation and the resulting acid rain, or means to capture carbon emissions from fossil fuel burning and subsequent sequestration in geologic formations deep underground. Declining energy returns on energy investment, however, do not only indicate that the material and energy base on which production and consumption depend is eroding; they also do not bode well for long-term prospects of economic growth. The upshot for environmental economics: the discipline must move beyond models of unidirectional coupling between economy and environment; expand its assessment of its resource base beyond simple stock estimates or material and energy balance accounts; and move beyond the naive capture of global harm in the form of temperature damage formulations.

But even if one sticks to the basic tenets of economic modeling, with its focus on economic growth and its presumed benefits to society, mere modifications to the underlying theory of production alone lead us to question the wisdom of traditional findings. Towards that end, Dodo Thampapillai and Matthias Ruth review in Chapter 7 the contributions by William Nordhaus and Paul Romer, both of whom were awarded the 2018 Nobel Prize in recognition of their contribution to the economics discipline, and whose work epitomizes modern growth theory. Simple expansions of their models to include natural capital alongside labor and humanmade capital are presented in which thermodynamic laws constrain resource use and ecosystems provide limited waste assimilation capacities. As a result of these very basic modifications, and otherwise sticking to conventional analysis, the Romer model suggests clear possibilities of the need for de-growth in selected economies. Furthermore, the Nordhausian goals of "optimal pollution" and "optimal climate change" are, at best, analytical artifacts and, at worst, detrimental to the health and wellbeing of society and the biophysical environment on which it depends. If the term "optimality" must be used, then the optimal quantity of pollution would be zero, which is physically impossible, and climate change would not occur, which for biogeophysical reasons cannot be the case either.

Since pollution and climate change occur, in essence, as consequences of energy use, the immediate question arises to what extent technological changes that reduce the need for energy per unit of desirable output can help society stay ahead of generating irreversible damages. How much can technical change run counter to the declining energy returns of investment discussed by Sers and Victor (Chapter 
6)? From a theoretical perspective, the laws of thermodynamics constrain material and energy efficiencies of any real-world process. In practical terms, however, a wide range of factors may play a critical role long before maximum thermodynamic efficiency is achieved. The long timeframes required to turn over capital stocks, including the national and global infrastructures on which they rely, also mean that little wiggle room often exists for considerable efficiency improvements, even when new "break-through technologies" are in principle known (Unruh 2000; Ruth et al. 2004). Additionally, there is the interplay of institutional developments with the deployment of technologies, as already explored by Faber and Frick (Chapter 3 ) and illustrated for the case of the soda-chlorine industry.

Other important drivers behind actual energy use and emissions profiles include international trade, which can help outsource energy- and pollution-intensive processes to other countries, thus reducing national environmental performance measures - though not necessarily benefitting the global system. And to the extent that trade, combined with efficiency improvements, stimulates growth at the sectoral or country level, the net result may be a reduction in the positive effects of efficiency gains on the environment. Improvements in industrial energy efficiency, for example, may make that industry more competitive by helping it drive down production cost and product price, which may increase its markets and thus its output at rates that are higher than the rate of the efficiency gains. Sectoral growth may stimulate demand for more machines and labor, all of which, in turn, will help fuel economic growth. This is precisely where the analysis by Astrid Kander, M. d. Mar Rubio-Varas and David Stern comes in. In their contribution (Chapter 8) they explore determinants for the gap between the rates of efficiency improvement, as measured in terms of energy use per unit of desired output, and observed rates of change in the energy use of the economy.

\subsection{Space, perception and behavior}

The concept of "environment" can have many different meanings in environmental economics - from a (generic) lake, forest or wetland, for example, whose qualitative features affect enjoyment by those seeking recreation in nature, to the more elusive notion of a stable climate or the more abstract concept of a system that provides materials and energy and receives the waste from their conversion. Rarely, however, are these manifestations of "environment" directly identified in space where they exist. Conversely, the location of people in space has a bearing on how they perceive their environment - not just in an abstract sense (more people, more consumption and thus more impact, for example) but also in the sense that geography matters; as do the associated cultural, social and psychological influences of placement in specific locations on the behaviors of people. It is this interplay of spatial context, values, attitudes and behaviors that lies at the center of Eveline van Leeuwen's chapter on place-based behavior (Chapter 9). Here, she concentrates on the differences in norms and behaviors between rural and urban areas and their implications for policy. To arrive at an understanding of these differences requires 
knowing the degree to which people "sort" by location as a result of their preferences and constraints - such as the availability of housing and amenities, financial resources, etc. - and how external factors affect behavior.

Drawing on data from the European Social Survey of 2016, van Leeuwen seeks to quantify the importance of the spatial context in values and behavior. Her analysis points towards a research agenda for environmental economics that makes contributions at both the micro and macro scale. At the micro scale, consumer choice must be viewed within its spatial context - the proximity to infrastructures such as transport systems and recycling centers, for example - and the opportunities this creates for action, learning and reinforcement of behaviors and norms. At the macro scale, an understanding of the regional dynamics at which externalities are generated, distributed and addressed through investment and policy choices is required to help shepherd development towards sustainable outcomes. And, of course, processes at the micro and macro scale shape each other, which in turn provides fertile ground for research into the relevance of place and space in shaping human-environment interactions.

In Chapter 10, Christian Krekel and Jens Kolbe explore ways to better understand and quantify the contributions urban ecosystems make to local economies. Traditional methods focus on monetary estimates based on stated preference methods, such as the contingent valuation approaches criticized by Sagoff in Chapter 2 . Hedonic pricing models, in essence, calculate the value of ecosystem services in the vicinity of settlements as a residual of housing prices that cannot be attributed to other aspects. By their very nature, such data deal with aggregate effects and may do little justice to the heterogeneous nature of ecosystems in urban settings. In contrast, vast amounts of data on human perceptions and actions are available through social media platforms, for example. Similarly, detailed characterizations of the state of ecosystems are becoming available at fine spatial resolution, such as chlorophyll and heat maps. The convergence of social and biophysical data then lends itself to quantifications of the contributions of ecosystems to local economies, and, conversely, to assessments of environmental impacts on those ecosystems. Again, as argued by van Leeuwen in the preceding chapter, space matters; and how the norms and behaviors discussed there relate to the changes in environmental values identified with new methods of "big data" analysis and machine learning-driven assessments discussed by Krekel and Kolbe may provide yet another avenue for research in environmental economics. Managing complex issues in a data-rich world is one of the endeavors that economists pride themselves on doing well.

A host of economic factors such as the disposable income of households or the profits of firms influence the level and mix of their production and consumption of goods and services, which in turn impact the environment. Furthermore, availability of financial resources of one shapes the performance of the other, for example when household consumption drives firm behavior or when production decisions influence employment, and thus incomes. Drilling down to the interactions between firm and household and their implications for environmental impact, 
Dana Andersen (Chapter 11) explores the role of credit constraints on composition of output in "clean" and "dirty" industries and the pollution intensity of production.

Firms that face more acute credit constraints tend to invest more in tangible assets such as machines and other forms of productive facilities at the expense of intangible assets such as the abilities and skill levels of their workforce. They do so largely because these tangible assets can serve as collateral against the credits they receive. This preference for tangible assets, in turn, shapes the short-term input mix of firms as well as factor endowments and patterns of production in the long run. The result of both these influences of credit constraints can also be seen in terms of industrial emissions profiles.

With the aid of a two-sector model of households and firms, Andersen illustrates the extent to which increases in human capital can draw resources from pollutionintensive sectors of the economy, leading to a more than proportional expansion of output in clean sectors and an absolute decline in output in dirty sectors. Aside from this direct impact on sector composition of the economy, an increase in human capital may also stimulate policy responses towards tighter environmental regulations whenever environmental quality is a normal good. Thus, credit constraints increase pollution whenever they impinge on investment in human capital. His findings are supported for the cases of sulfur dioxide and lead emissions, using World Health Organization data for about 150 cities in 45 countries, and suggest that policies aimed at promoting human capital or the development of human capital-intensive industries, might be effective at promoting development in a way that is less environmentally damaging than development based on physical capital accumulation.

Indeed, policies of all kinds shape short- and long-run environmental performance, and they also lead to winners and losers within the industrial sector. Given the complexity of economy-environment interactions, the dynamic nature of firm behavior and technology change, the evolution of preferences of people in the context of ever-changing economic and environmental conditions, considerable uncertainties surround, at least a priori, the effectiveness of proposed policies. Both the winners and losers may exploit these uncertainties to their benefit, and they may even take an active role not just in identifying uncertainties but by generating doubt and providing misinformation. Even where science shows pretty clear-cut relations between human activity and environmental change, strategies to distort science or poo-poo facts as "fake news" can have far-reaching implications for the support by society for environmental regulation.

In their chapter (Chapter 12) on the manufacture of doubt, Yann Bramoulle and Caroline Orset attend to these unscrupulous practices, which so far have been largely neglected by economists. They develop a simple model composed of four groups of actors. In this model, firms generate emissions and also may decide to produce costly reports that portray their emissions as not being harmful. Scientists carry out research that reduces uncertainty about the impacts of emissions. Citizens 
receive information from firms and scientists and are unaware when misinformation is presented to them. Governments consider public opinion when determining the degree of regulation of the pollution generated by firms. With this model, Bramoullé and Orset lay out a range of developments that characterize the actions of industry and science, as well as the responses by government. For example, as scientists become increasingly convinced that industrial activity is harmful, industry first devotes more resources to falsely reassure citizens that industrial pollution is benign. When scientific belief reaches a critical threshold, however, firms find it too costly to counter scientific consensus and industry abruptly ends its misinformation. These results are shown to hold whether a command and control approach is used by government to curb emissions or a tax on emissions is chosen. Bramoullé and Orset argue for a wide range of refinements of their model, such as decision making over multiple periods, and the inclusion of multiple lobbies and multiple lobbying strategies. They call for the present specification of belief formation and preferences concerning risk to be refined, and for the representations of the role of science and scientists to be more nuanced. Their detailed exposé of each of these refinements charts the course for an environmental economics that is indeed responsive to the many real and pressing social and political challenges alluded to by Sagoff in Chapter 2, and that occupy the daily headlines of newspapers, TV shows and radio programs of the "post-truth era" in which we currently find ourselves.

And talking of real and pressing problems - there is a big section of human society whose daily challenges have not, by any measure, received the attention they need. These are the large numbers of marginalized people, especially those who live in the global south, the rural areas or city districts with limited access to safe drinking water, clean air, healthy food, and much more. The challenges they face are oftentimes caused, or exacerbated, by the very environmental issues that are core topics in environmental economics. Yet, these are also less glamorous topics. Dealing with the provision of sanitary services in urban slums, where there is no organized voice to speak on behalf of those who have no other option but to defecate in the open, is different from addressing the emissions challenges of the US paper industry, for example, with shareholders, workers and environmentalists organized around the topic, all with resources to fund research and to advice investment and policy making.

René Kemp and Shyama Ramani draw on experiences in India to advocate for a solution design approach that explicitly involves stakeholders to address some of the challenges associated with the transition towards production and consumption processes that are moving society towards sustainability (Chapter 13). They point to the sunk costs associated with existing technologies and infrastructures on the one hand, and institutional rigidities and social structural behaviors on the other that have mutually reinforced each other. At a more fundamental level, though, the solution design approach will require, almost as a prerequisite, environmental economists to embrace as valid and urgent the many messy problems of everyday people in dire situations - the urban and rural poor, young and old, in developing 
countries. Given the complexities of such situations, all relevant actors at the heart of the problem must be present at all stages of the transition process - from identification of the causes to the design of remedies, the monitoring of implementation efforts and outcomes, and revisions as necessary. This is a fundamentally different approach from the rather prescriptive, historically largely abstract approach of modern environmental economics: an approach that is organic in nature; one that recognizes the co-evolution of social and environmental change; one that gives voice to the voiceless; and one that shares knowledge to achieve sustainability rather than one that prescribes, advises and delegates.

Reinforcing and expanding on the vision articulated by Kemp and Ramani, Jalel Sager and Richard Norgaard (Chapter 14) explore the human dilemma through a co-evolutionary framing and acknowledgment of the interwoven nature of values, knowledge, technology, social organization and the environment. They return to the global challenges posed at the beginning of this volume and found in almost all of its chapters - the immense strides humans have made through the exploitation of fossil fuel reserves to raise standards of living and transform the world around them by building infrastructures and institutions intended to help with the perpetuation of economic growth and prosperity. At the same time, these transformations have also irreversibly altered biogeochemical cycles, undermined the abilities of ecosystems to provide valuable waste assimilation services and habitats for other species, and moved climate dynamics towards tipping points beyond which all bets for future prosperity are off. In the wake of these developments, global and national systems of power and socio-political organization have formed that, so far, have reinforced inequalities and injustices and pitted one part of the globe or one part of society against another in the race for prosperity, as if it all were a zero-sum game.

But are we really playing a zero-sum game? Isn't there a solution in which the abilities of the Earth's ecosystems to provide continued enjoyment and life support are protected, in which those who are worse off will be attended to and those who do the attending benefit as well - in ways other than just cheap profit motives? What are the theories and methods that do justice to the human nature of production and consumption decisions in a finite world? How do we shape our political economy to be in tune with human, social needs rather than the simplistic assumptions of nineteenth-century optimization of individuals' utilities? And yet, what are the insights from prior theories and applications that can and must be salvaged as humanity grapples with the challenges that lie ahead? These are some of the fundamental questions that should shape a research agenda for environmental economics. And these are, indeed, the questions addressed in this volume. Asking them is a first important step. Pointing towards ways to answer them, as the many contributors have done here, helps create momentum for the discipline, and hopefully motivates others to add their intellectual weight, effort and support behind them. This is a call for all hands on deck to shape how the discipline of environmental economics treats the coupled human-environment system and the way it conceives of its role 
in the discourse about the future of humanity and our environment, before it is truly too late.

\section{References}

Brown, P. and Garver, G. 2009. Right Relationship: Building a Whole Earth Economy, San Francisco: Berrett-Koehler.

Holcombe, R.G. 2014. Advanced Introduction to the Austrian School of Economics, Cheltenham, UK and Northampton, MA, USA: Edward Elgar Publishing.

Motesharrei, S., J. Rivas, E. Kalnay, G. Asrar, A. Busalacchi, R. Cahalan, M. Cane, R. Colwell, K. Feng, R. Franklin, K. Hubacek, F. Miralles-Wilhelm, T. Miyoshi, M. Ruth, R. Sagdeev, A. Shirmohammadi, J. Shukla, J. Srebric, V. Yakovenko and Ning Zeng. 2016. The Essential Need for Bidirectional Coupling of Earth System and Human System Models, National Science Review, Vol. 3, pp.470-494, doi: 10.1093/nsr/nww081.

Røpke, I. 1999. Prices are not worth much, Ecological Economics, Vol. 29, No. 1, pp.45-46.

Ruth, M., B. Davidsdottir and A. Amato. 2004. Climate Change Policies and Capital Vintage Effects: The Cases of US Pulp and Paper, Iron and Steel and Ethylene, Journal of Environmental Management, Vol. 7, No. 3, pp. 221-233.

Ruth, M. 2018. Regional Science in a Resource-constrained World, Annals of Regional Science, Vol. 62, No. 2, pp. 229-236, https://doi.org/10.1007/s00168-018-0879-0.

Unruh, G.C. 2000. Understanding Carbon Lock-in, Energy Policy, Vol. 28, No. 12, pp. 817-830. 